\title{
Attitudes of Medicare-Eligible Americans Toward Mail Service Pharmacy
}

\author{
Michael T. Rupp, PhD, BPharm, FAPhA
}

\begin{abstract}
BACKGROUND: For many years, community pharmacies provided mail delivery as a convenience for a small segment of special circumstance patients who requested it. Fueled by a movement among plan sponsors and prescription benefit managers to encourage or require its use, growth in mail service pharmacy began to accelerate in the 1980s and now accounts for nearly $25 \%$ of the market in the general population and a much higher percentage of seniors.
\end{abstract}

OBJECTIVE: To assess the attitudes of Medicare-eligible Americans toward concerns that have been raised about mail service pharmacy and its mandated use in the prescription benefit plans of public and private insurance programs.

METHODS: Existing published literature was reviewed, and interviews were conducted with Medicare-eligible persons aged 65 and older to identify potential areas of concern with mail order pharmacy services. A survey was constructed and mailed to a nationally representative random sample of 6,500 persons between the ages of 65 and 79 in July 2012.

RESULTS: By the cutoff date, 669 completed surveys had been received, and an additional 221 had been returned as undeliverable, resulting in an overall response rate of $10.7 \%$. Nearly half of respondents listed chain pharmacy as their primary source of prescription medications $(47.7 \%)$ followed by mail service $(34.1 \%)$, independent pharmacy (13.1\%), and other (5.1\%). Responses of seniors residing in rural ZIP codes compared with those in nonrural ZIP codes demonstrated significantly higher agreement with several concerns, including lost or stolen medications, receiving the exact medication the physician prescribed, and the effects of exposure to heat, cold, or moisture. Two additional concerns approached statistical significance: the ability to speak with a pharmacist face-to-face and the ability to obtain medications quickly if needed. A total of $533(83.7 \%)$ indicated they would oppose mandated mail order in their current benefit plan if it would cause the local community pharmacy they rely on for immediate medication needs to close. The mean risk of such an eventuality that respondents were willing to accept was $42.2 \%$, indicating they would oppose mandatory mail order if there were greater than about a 4-in-10 chance it would cause the loss of their local pharmacy.

CONCLUSIONS: Seniors appear to be practical and pragmatic about the sources of their prescription medications. While most see a role for mail service pharmacy, they are also aware of its limitations. Many have needs they believe cannot be adequately met by mail service or have relationships with local pharmacies and pharmacists they believe are important for maintaining their health and well-being. As a result, seniors are relatively risk averse when it comes to the loss of their local community pharmacy, even if they routinely use mail order for most of their medications. Beyond their specific concerns, most seniors oppose any restrictions on their freedom to use the pharmacy of their choice on general principle.

J Manag Care Pharm. 2013;19(7):564-72

Copyright $\odot 2013$, Academy of Managed Care Pharmacy. All rights reserved.

\section{What is already known about this subject}

- From 6\% of the U.S. prescription drug market in the late 1980s, mail order now accounts for $23.5 \%$ and has significantly higher use in the senior population.

- More than $97 \%$ of employers report offering a mail order option to employees, and $23 \%$ require the use of mail order for maintenance prescriptions

- Research has challenged the cost advantages of mail order to plan sponsors and concerns have been raised about the implications of mandating mail order in prescription benefit plans.

\section{What this study adds}

- Many seniors believe they have needs that cannot be adequately met by mail service or have relationships with local pharmacies and pharmacists they believe are important for maintaining their health and well-being.

- Seniors living in rural ZIP codes have significantly greater concerns than those in nonrural ZIP codes about the potential for lost or stolen medications, receiving the exact medication the physician prescribed, and the effects of exposure to heat, cold, or moisture on prescription medications.

- Beyond specific concerns that some seniors have about mail service pharmacy, most appear to oppose any restrictions on their freedom to use the pharmacy of their choice on general principle.

- Even among those who use and are generally satisfied with mail service pharmacy, seniors are relatively risk averse when it comes to the loss of their local community pharmacy.

$\mathrm{F}$ or many years, community pharmacies have delivered prescription medications to the homes of selected patients via U.S. mail or courier services. Mail delivery was traditionally provided as a convenience to a small segment of special circumstance patients who requested it for reasons such as mobility impairment, rural or remote location, illness, or temporary relocation.

Beginning in the 1980s, the growth in mail service pharmacy began to accelerate. From approximately $6 \%$ of the U.S. outpatient prescription drug market in the late 1980s, the mail order market share doubled to $12 \%$ in $2000 .{ }^{1}$ By 2010 , its market share had doubled again to $23.5 \%$ in the general population, 
and the proportion of seniors (aged 65 and older) who use mail order is reported to be significantly higher. ${ }^{2,3}$

The growth in mail service has been fueled by a movement among health insurance benefit plan sponsors and prescription benefit managers to encourage or require the use of mail service pharmacy among covered beneficiaries. ${ }^{4}$ In a 2010 survey of 62 employer members of the National Business Group on Health, $47 \%$ reported the use of mandatory mail order for maintenance medications. ${ }^{5}$ A 2012 survey of 424 employers by the Pharmacy Benefit Management Institute reported that $97.6 \%$ offer a mail service pharmacy option to employees, and $23 \%$ required maintenance medications to be dispensed by mail order, up from only $18 \%$ the year before. ${ }^{6}$

The rapid adoption of mail order by employers has occurred despite concerns that have been raised about its ability to control costs to plan sponsors. An analysis by Carroll et al. (2005) concluded that mail service pharmacy was less expensive for the patient but more expensive for the health plan. ${ }^{7}$ A subsequent study by Johnsrud et al. (2007) confirmed this finding, concluding that although consumers netted an overall savings benefit from mail order, this benefit did not extend to plan sponsors. ${ }^{8}$ In a study of military beneficiaries age 65 and older, Linton et al. (2007) found many elected not to use the mail order program despite the financial incentive to do so, choosing instead to use a community pharmacy. ${ }^{9}$

A 2011 study found that $31.8 \%$ of commercially insured patients who were previously required to use mail service pharmacy elected to have their prescriptions filled at community pharmacies when they were allowed to purchase 90-day supplies with no difference in out-of-pocket costs. Among those who had previously used a community pharmacy, the preference rate jumped to $66.3 \%$. The authors concluded that "when pharmacy benefit design does not preferentially support one pharmacy distribution channel, both community pharmacy and mail service pharmacy appeal to patients."10

The specter of mandatory mail order has raised numerous concerns among patients, employers, community pharmacists, and policymakers. The 2012 U.S. Pharmacy Survey by J.D. Power and Associates found that "satisfaction among customers who use mail order pharmacies to fill their prescriptions has fallen significantly below customer satisfaction with brick and mortar pharmacies," and that patient satisfaction with mail order declined for the second consecutive year. ${ }^{11}$

Beyond continuing questions about the purported cost advantages of mail order and the broad philosophical issue of the consumer's freedom to choose pharmacy providers, specific concerns have been raised about a variety of other considerations, including safety, security, convenience, confidentiality, product integrity, and waste of mail service pharmacy. Although mostly anecdotal, these concerns continue to represent unanswered questions about how consumers view the consequences of current or future mandatory mail order provisions of prescription drug benefit programs.

The objective of this study was to empirically assess the attitudes of Medicare-eligible Americans toward mail service pharmacy and its mandated use in prescription drug benefit plans of public and private insurance programs. Of particular interest were consumers' attitudes toward frequently cited concerns of mail order pharmacy, including the following:

- Cost of mail order to the plan sponsor, especially when considering waste

- Convenience of mail order when considering timeliness of delivery

- Reliability of uninterrupted therapy

- Substitution of medications for those originally prescribed by their physician

- Medication storage relative to environmental conditions such as heat, cold, and humidity

- Medication security

- Medication confidentiality

- Accessibility to a pharmacist for questions or counsel

- Safe disposal of excess or discontinued medications

- Continued economic viability of local community pharmacies for acute or urgent needs

\section{Methods}

The survey included a series of descriptive demographic questions regarding gender, age, residential ZIP code, and drive time to the nearest community pharmacy. Additional questions asked about past experience with mail service pharmacy and whether the respondent was currently enrolled in Medicare.

Attitudes toward concerns that have been raised about mail service pharmacy were measured via a series of statements that required respondents to select a response from a 5-point Likert-type scale. The survey also asked whether the respondent would oppose a mandated mail order requirement in their prescription benefit plan if it would cause the local pharmacy they relied on for immediate medication needs to close.

This question was included on the survey because it has been suggested that the loss of maintenance medications to mail order could threaten the continued financial viability of some community pharmacies. To be clear, this scenario continues to be largely speculative, as empirical evidence that mail order pharmacy has driven community pharmacies out of business is lacking in the published literature. The purpose of this question was not to evaluate the validity of mail order's purported threat to the financial viability of community pharmacies, but rather to assess how risk averse senior Americans are to losing their local community pharmacy providers in such an eventuality. 


\section{TABLE 1 Attitudes Toward Mail Service Pharmacy}

\begin{tabular}{|c|c|c|c|c|c|c|}
\hline Survey Item & $\mathrm{N}$ & $\begin{array}{c}\% \\
\text { Strongly } \\
\text { Agree }\end{array}$ & $\begin{array}{c}\% \\
\text { Agree }\end{array}$ & $\begin{array}{c}\% \\
\text { Neutral }\end{array}$ & $\begin{array}{c}\% \\
\text { Disagree }\end{array}$ & $\begin{array}{c}\% \\
\text { Strongly } \\
\text { Disagree }\end{array}$ \\
\hline $\begin{array}{l}\text { 1. Getting prescriptions by mail is less expensive than getting them filled at a local } \\
\text { pharmacy. }\end{array}$ & 632 & 19.5 & 32.1 & 31.2 & 9.2 & 8.1 \\
\hline $\begin{array}{l}\text { 2. If I used a mail order pharmacy I would be concerned about running out of my } \\
\text { medications. }\end{array}$ & 655 & 16.9 & 24.1 & 19.1 & 25.5 & 14.4 \\
\hline $\begin{array}{l}\text { 3. If I used a mail order pharmacy I would be concerned about whether I fully } \\
\text { understood my medications and how to take them. }\end{array}$ & 654 & 12.1 & 16.1 & 20.8 & 35.0 & 16.1 \\
\hline $\begin{array}{l}\text { 4. If I used a mail order pharmacy I would be concerned that I could not talk face- } \\
\text { to-face with a pharmacist. }\end{array}$ & 658 & 19.3 & 21.9 & 20.4 & 26.1 & 12.3 \\
\hline $\begin{array}{l}\text { 5. If I used a mail order pharmacy I would be concerned that my medications } \\
\text { could be lost or stolen. }\end{array}$ & 656 & 17.1 & 23.0 & 17.8 & 31.1 & 11.0 \\
\hline $\begin{array}{l}\text { 6. If I used a mail order pharmacy I would be concerned about whether I was } \\
\text { getting the exact medication my doctor ordered. }\end{array}$ & 657 & 15.7 & 19.2 & 19.2 & 31.8 & 14.2 \\
\hline $\begin{array}{l}\text { 7. If I used a mail order pharmacy I would be concerned about the effects of } \\
\text { excessive heat, cold, or moisture on my medications. }\end{array}$ & 660 & 17.9 & 23.9 & 21.2 & 26.5 & 10.5 \\
\hline $\begin{array}{l}\text { 8. If I used a mail order pharmacy I would be concerned about waste when my } \\
\text { medications are changed or discontinued. }\end{array}$ & 657 & 15.5 & 25.4 & 26.2 & 25.4 & 7.5 \\
\hline $\begin{array}{l}\text { 9. If I used a mail order pharmacy I would be concerned about getting my } \\
\text { medications quickly when I need them right away. }\end{array}$ & 657 & 25.9 & 33.9 & 13.9 & 19.2 & 7.2 \\
\hline $\begin{array}{l}\text { 10. If I were required to use a mail order pharmacy I would be concerned about } \\
\text { losing my freedom to use the pharmacy of my choice. }\end{array}$ & 661 & 34.6 & 28.3 & 13.0 & 17.1 & 7.0 \\
\hline $\begin{array}{l}\text { 11. If I were required to use a mail order pharmacy I would be concerned about } \\
\text { not having a pharmacist who knows me and the medications I take. }\end{array}$ & 662 & 29.9 & 25.4 & 17.8 & 19.9 & 6.9 \\
\hline
\end{tabular}

Those who indicated they would oppose mandated mail order in such a circumstance were subsequently asked to indicate the highest level of risk they would be willing to accept by circling the appropriate value on the following visual analog scale:

I would oppose mandated mail order if the risk that it would cause my local pharmacy to close were any higher than (circle the appropriate value below)

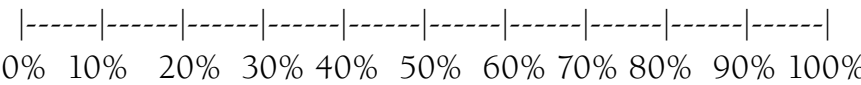

The survey concluded with 2 open-ended questions that allowed respondents to express how the closure of their local community pharmacy would affect their lives, as well as any additional comments or concerns they had related to mail service pharmacy.

A pilot survey was mailed to 500 persons from a nationally representative random sample of 6,500 persons between the ages of 65 and 79 in July 2012. The mailing list was obtained from USA Data (http:usadata.com). The study sample was proportionately representative of the relative population of each of the 50 states. Also enclosed were a cover letter and a stamped return envelope. Forty-eight usable responses were returned for a response rate of $9.9 \%$, as 13 surveys were eventually returned as undeliverable.
Following analysis of responses from the pilot, 1 question was added to the survey: "If you use a mail order pharmacy, how often do you speak with a mail order pharmacist about your medications?"

In August 2012, surveys were mailed to the remaining 6,000 persons on the mailing list. Once again, each envelope contained the survey, a cover letter, and a stamped return envelope.

\section{Results}

By the cutoff date of October 15, 2012, 669 completed surveys had been returned. Of the 6,500 surveys mailed, 221 (3.4\%) were eventually returned as undeliverable, resulting in an overall response rate of $10.7 \%$, of which $57.0 \%$ were female and $43.0 \%$ were male.

The average age of survey respondents was 72.4 years (median $=72$, standard deviation $[S D]=4.4$ ). Although a range of 65-79 years was used as a selection criterion in generating the mailing list that was used in the study, 28 respondents reported being over 79 years of age. As these met the minimum age criterion, they were retained for analysis. The 669 respondents resided in 644 ZIP codes in 43 states. No surveys were returned from Alaska, Maine, Massachusetts, New Hampshire, North Dakota, Rhode Island, and Vermont.

Response rates by region indicated there were no significant differences $(P<0.05)$ between the survey sample and respondents according to the geographic classification system that is used by the U.S. Census Bureau. ${ }^{12}$ 
When asked to describe their health status, $56.1 \%$ of respondents indicated "Good" followed by "Fair" (22.8\%), "Excellent" (17.8\%), and "Poor" (3.3\%). Most (98.1\%) respondents indicated they were currently enrolled in Medicare.

Respondents reported taking an average of 4.6 different prescription medications each day that had been prescribed by an average of 1.6 physicians. The mean drive time to the nearest pharmacy was reported to be 9.1 minutes. Drive time was used because it is considered to be a more relevant indicator of access than geographic distance.

Almost half $(47.7 \%)$ of respondents listed chain pharmacy as their primary source of prescription medications, followed by mail service (34.1\%), independent pharmacy (13.1\%), and other (5.1\%). Most respondents who selected "other" specified their primary source of prescription drugs as the Veterans Health Administration (VA). Slightly more than one-third of respondents (34.2\%) indicated they rely on an independent community pharmacy for at least some of their prescription medication needs.

When asked if they are currently required to use mail order for some of their medications, $12.3 \%$ indicated affirmatively, while $56.7 \%$ have used mail order for prescriptions in the past. Among those who currently use either voluntary or mandatory mail order, respondents indicated they speak to a mail order pharmacist 2.1 times per year on average.

\section{Attitudes Toward Mail Service Pharmacy}

The survey contained 11 statements designed to assess respondents' attitudes toward specific concerns that have been raised about mail order pharmacy. Respondents indicated their agreement with each statement by selecting the response from a 5-point Likert-type scale that best reflected their opinion: Strongly Agree, Agree, Neutral, Disagree, Strongly Disagree.

Scale reliability was assessed by calculating Cronbach's coefficient alpha, a commonly used measure of internal consistency that varies from 0 to $1 .{ }^{13}$ An alpha value $\geq 0.7$ is generally considered acceptable and a value $\geq 0.9$ is considered excellent. The internal consistency for the 11-item scale used in this project was calculated to be $\alpha=0.905$.

As illustrated in Table 1, when asked if using mail order pharmacy is less expensive than using a local pharmacy, a slight majority (51.6\%) indicated they agreed or strongly agreed while nearly half of respondents were neutral $(31.2 \%)$ or disagreed (17.3\%) with this statement (item 1).

When asked if they would be concerned about running out of their medication if they used a mail order pharmacy, $41 \%$ of respondents agreed or strongly agreed while a slightly smaller percentage (39.8\%) disagreed with this statement (item 2).

When asked if they would be concerned about whether they fully understood their medications and how to take them if they used a mail order pharmacy, a slight majority (51.1\%) disagreed while over a quarter of respondents (28.2\%) agreed or strongly agreed (item 3).
When asked if they would be concerned about not being able to speak face-to-face with a pharmacist if they used a mail order pharmacy, $41.2 \%$ of respondents agreed or strongly agreed while slightly over 20\% were neutral and 38.4\% disagreed. Notably, the percentage of respondents who strongly agreed with this statement (19.3\%) was significantly higher than those who strongly disagreed at $12.3 \%$ (item 4).

Slightly more than $40 \%$ of respondents agreed or strongly agreed they would be concerned about their medications being lost or stolen if they used a mail order pharmacy. A somewhat higher percentage (41.1\%) disagreed with this statement. Again, the percentage of respondents that strongly agreed was significantly higher than that which strongly disagreed (item 5).

Regarding the integrity of mail order medications, $34.9 \%$ of respondents agreed they would be concerned about whether the medication they received was exactly the same as that which the physician had prescribed. A slightly higher percentage (46\%) disagreed with this statement (item 6).

When asked if they would be concerned about the effects of heat, cold, or moisture on their medications if they used a mail order pharmacy, $41.8 \%$ indicated they would while 37\% disagreed with this statement. Once again, the percentage of those who strongly agreed with this statement was significantly higher than those who disagreed (item 7).

A higher percentage of respondents (40.9\%) agreed than disagreed (32.9\%) that they would be concerned about waste when their prescriptions were changed or discontinued if they used a mail order pharmacy. The percentage of those who strongly agreed with this statement was more than twice that of those who strongly disagreed (item 8).

Nearly $60 \%$ of respondents agreed they would be concerned about getting their medications when they needed them right away if they used mail order pharmacy. In contrast, 26.4\% disagreed with this statement (item 9).

In the event they were required to use a mail order pharmacy, $62.9 \%$ of respondents agreed they would be concerned about losing their freedom to use the pharmacy of their choice. Only $24.1 \%$ of respondents disagreed with this statement (item 10).

If required to use a mail order pharmacy, 55.3\% agreed they would be concerned about not having a pharmacist who knows them and the medications they take. In contrast, 26.8\% of respondents disagreed with this statement (item 11).

To assess the impact that geographic location has on seniors' attitudes toward mail order pharmacy, each respondent was classified as either rural or nonrural based on their residential ZIP code using the criteria employed by the Centers for Medicare and Medicaid Services (CMS). ${ }^{14}$ Responses to the 11 Likert-scaled survey items were then recoded as numeric values and means were generated for both groups. Differences between means were calculated using paired t-tests. The results appear in Table 2. 
Survey Item

1. Getting prescriptions by mail is less expensive than getting them filled at a local pharmacy.

2. If I used a mail order pharmacy I would be concerned about running out of my medications.

3. If I used a mail order pharmacy I would be concerned about whether I fully understood my medications and how to take them.

4. If I used a mail order pharmacy I would be concerned that I could not talk face-to-face with a pharmacist.

5. If I used a mail order pharmacy I would be concerned that my medications could be lost or stolen.

6. If I used a mail order pharmacy I would be concerned about whether I was getting the exact medication my doctor ordered.

7. If I used a mail order pharmacy I would be concerned about the effects of excessive heat, cold or moisture on my medications.

8. If I used a mail order pharmacy I would be concerned about waste when my medications are changed or discontinued.

9. If I used a mail order pharmacy I would be concerned about getting my medications quickly when I need them right away.

10. If I were required to use a mail order pharmacy I would be concerned about losing my freedom to use the pharmacy of my choice.

11. If I were required to use a mail order pharmacy I would be concerned about not having a pharmacist who knows me and the medications I take.

\begin{tabular}{|c|c|c|c|c|c|c|}
\hline \multicolumn{3}{|c|}{ Rural } & \multicolumn{3}{|c|}{ Nonrural } & \multirow{2}{*}{$\begin{array}{c}P \\
\text { Value }\end{array}$} \\
\hline $\mathrm{N}$ & Mean & SD & $\mathbf{N}$ & Mean & SD & \\
\hline 142 & 3.35 & 1.23 & 490 & 3.49 & 1.12 & 0.1041 \\
\hline 145 & 3.07 & 1.42 & 51 & 3.03 & 1.29 & 0.3817 \\
\hline 145 & 2.78 & 1.31 & 509 & 2.72 & 1.24 & 0.3049 \\
\hline 144 & 3.24 & 1.34 & 514 & 3.06 & 1.31 & 0.0695 \\
\hline 144 & 3.21 & 1.34 & 512 & 3.00 & 1.27 & 0.0443 \\
\hline 142 & 3.08 & 1.34 & 515 & 2.86 & 1.29 & $0.0405^{a}$ \\
\hline 144 & 3.29 & 1.31 & 516 & 3.08 & 1.26 & $0.0396^{a}$ \\
\hline 144 & 3.21 & 1.22 & 513 & 3.15 & 1.18 & 0.2996 \\
\hline 143 & 3.66 & 1.26 & 514 & 3.48 & 1.26 & 0.0635 \\
\hline 144 & 3.71 & 1.33 & 517 & 3.65 & 1.29 & 0.3305 \\
\hline 145 & 3.54 & 1.34 & 517 & 3.51 & 1.28 & 0.3746 \\
\hline
\end{tabular}

a Difference between means of rural versus nonrural respondents $P<0.05$

$S D=$ standard deviation

Also indicated in Table 2, the responses of seniors residing in rural ZIP codes demonstrated significantly higher agreement with statements related to concerns about lost or stolen medications (item 5), receiving the exact medication the physician prescribed (item 6), and the effects of exposure to heat, cold, or moisture (item 7). Two additional survey items approached statistical significance: the ability to speak with a pharmacist face-to-face (item 4) and ability to obtain medications quickly if needed (item 9).

Another question of interest was whether respondents who have used mail order pharmacy differ significantly in their attitudes from those who have not. To assess this question, each respondent was classified as "user" or "nonuser" and paired t-tests were calculated between means. The results of this analysis appear in Table 3.

The results indicated that respondents who had previously used mail service pharmacy had significantly higher agreement to item 1 (mail order is less expensive) than nonusers. For all remaining items, previous users had significantly lower agreement than nonusers. It should be noted, however, that both groups had mean agreement above neutrality for item 9 (getting my medications quickly when I need them), item 10 (freedom of choice), and item 11 (having a pharmacist who knows me and the medications I take). Thus, while both users and nonusers had net positive agreement to these items, nonusers demonstrated significantly stronger agreement than users.

When respondents were asked if they would oppose man- dated mail order if it would cause the local community pharmacy they rely on for immediate medication needs to close, $533(83.7 \%)$ said "Yes." Respondents who indicated they would oppose mandated mail order if it would cause their local pharmacy to close were subsequently asked to indicate the highest level of risk they would be willing to accept for this eventuality by circling the appropriate value on the visual analog scale. Of the 482 responses to this question, the mean risk that respondents were willing to accept was $42.2 \%$. That is, respondents indicated they would oppose mandatory mail order if there were greater than about a 4-in-10 chance that it would cause the loss of their local pharmacy.

To estimate the extent to which nonresponse may have represented a potential threat to validity, survey responses that were received within 7 calendar days of mailing were compared with those received later. The reasoning behind this analysis is the assumption that late responders are more likely to reflect the sentiments of nonrespondents. Thus, if a significant difference is found between early and late responders, it suggests that nonresponse bias may represent a threat to validity as the attitudes of respondents may not be representative of nonrespondents.

Of the 482 respondents to the risk assessment question, early responders had a mean of $42.5 \%(n=387)$, while late responders had a mean of $40.8 \%(n=85)$. A two-sample t-test revealed no significant differences between the 2 means. 
Survey Item

1. Getting prescriptions by mail is less expensive than getting them filled at a local pharmacy.

2. If I used a mail order pharmacy I would be concerned about running out of my medications.

3. If I used a mail order pharmacy I would be concerned about whether I fully understood my medications and how to take them.

4. If I used a mail order pharmacy I would be concerned that I could not talk face-to-face with a pharmacist.

5. If I used a mail order pharmacy I would be concerned that my medications could be lost or stolen.

6. If I used a mail order pharmacy I would be concerned about whether I was getting the exact medication my doctor ordered

7. If I used a mail order pharmacy I would be concerned about the effects of excessive heat, cold or moisture on my medications.

8. If I used a mail order pharmacy I would be concerned about waste when my medications are changed or discontinued.

9. If I used a mail order pharmacy I would be concerned about getting my medications quickly when I need them right away.

10. If I were required to use a mail order pharmacy I would be concerned about losing my freedom to use the pharmacy of my choice.

11. If I were required to use a mail order pharmacy I would be concerned about not having a pharmacist who knows me and the medications I take.

a Difference between means of users versus nonusers $P<0.05$.

$S D=$ standard deviation

\section{Respondent Comments}

When survey respondents were asked to describe how the loss of their local community pharmacy would affect them, 265 (39.6\%) provided written comments that cited a total of 402 negative effects. These anticipated effects of local pharmacy closure were subsequently classified according to their core themes as illustrated in Figure 1.

Inconvenience resulting from the effort required to secure an alternative pharmacy (22.9\%) and reduced access to medications for urgent or acute care situations (21.9\%) represented the most frequently cited negative effects of local pharmacy closure. The loss of a valued personal relationship with the pharmacist was cited by $14.9 \%$, followed closely by feelings of worry, fear, stress, or sadness (13.7\%).

More than 1 in 10 (10.7\%) respondents cited concerns that the loss of the local community pharmacy would adversely affect the quality of their health care, and $6.2 \%$ indicated it would have a negative impact on their community's health or economic viability. The loss of other (i.e., nonprescription) products and services that seniors rely on their local community pharmacy for was mentioned by $4.2 \%$ of respondents, underscoring the importance of the community pharmacy for fulfilling a variety of additional needs. The fear that losing their local pharmacy would lead to higher prices for their prescrip- tion medications was cited by $4.0 \%$, and $1.5 \%$ indicated that losing their local pharmacy would make them angry.

Finally, when respondents were asked if they wished to share any additional comments or concerns about mail order pharmacies or prescriptions, 238 (35.6\%) provided written comments. Each comment was reviewed to determine whether the attitude toward mail order was positive, negative, or both. Comments were subsequently subjected to content analysis to categorize each comment by theme (Figure 2).

The majority of comments that were received (71.4\%) expressed a negative attitude toward mail order pharmacy. However, $17.1 \%$ were positive, and another $11.3 \%$ contained both positive and negative elements. Thus, $82.7 \%$ of comments contained one or more concerns and/or negative attitudes toward mail order pharmacy, while $28.5 \%$ contained one or more positive themes.

The most frequently expressed concern about mail order was seniors' opposition to any mandate that would limit their right to use the pharmacy of their choice (30.8\%). Of the $96 \mathrm{com}-$ ments that mentioned this theme, the term "un-American" or a close facsimile was used frequently. Previous negative experiences with the use of mail order pharmacy were cited in 15.7\% of comments, often paired with one or more specific examples. 


\section{FIGURE 1 Effect of Local Community Pharmacy Closure}

\section{How would losing your community pharmacy affect you?}

$(n=402)$

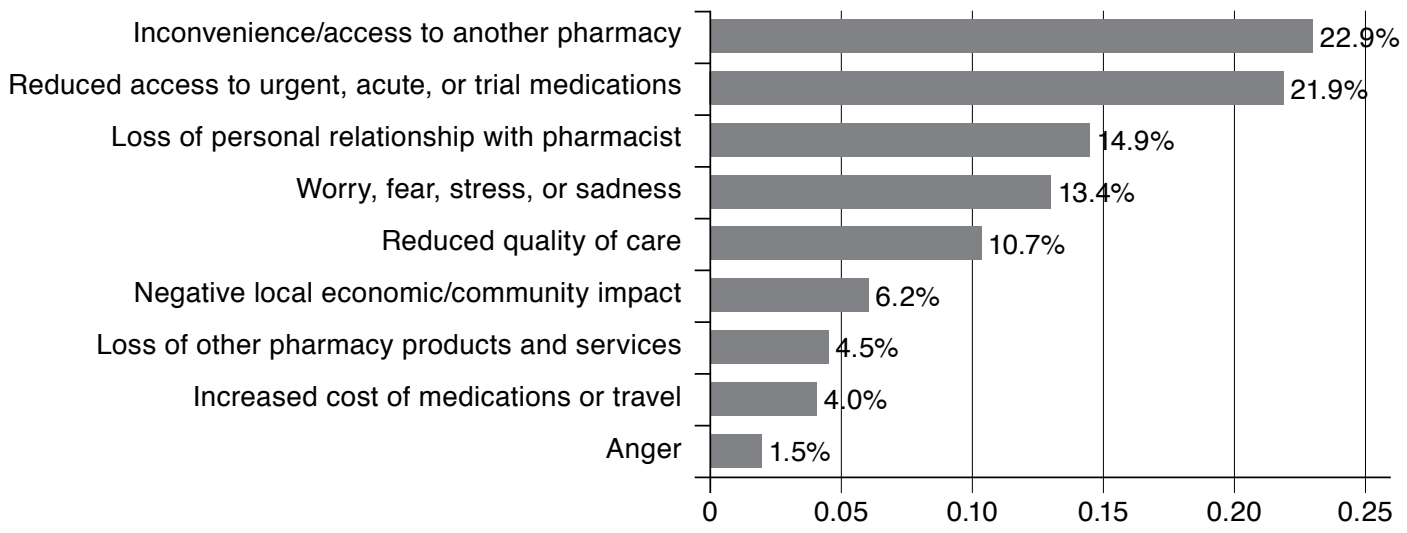

\section{FIGURE 2 Comments on Mail Order Pharmacy}

What additional comments or concerns about mail order pharmacies or mandated mail order prescriptions would you like to share? $(n=312)$

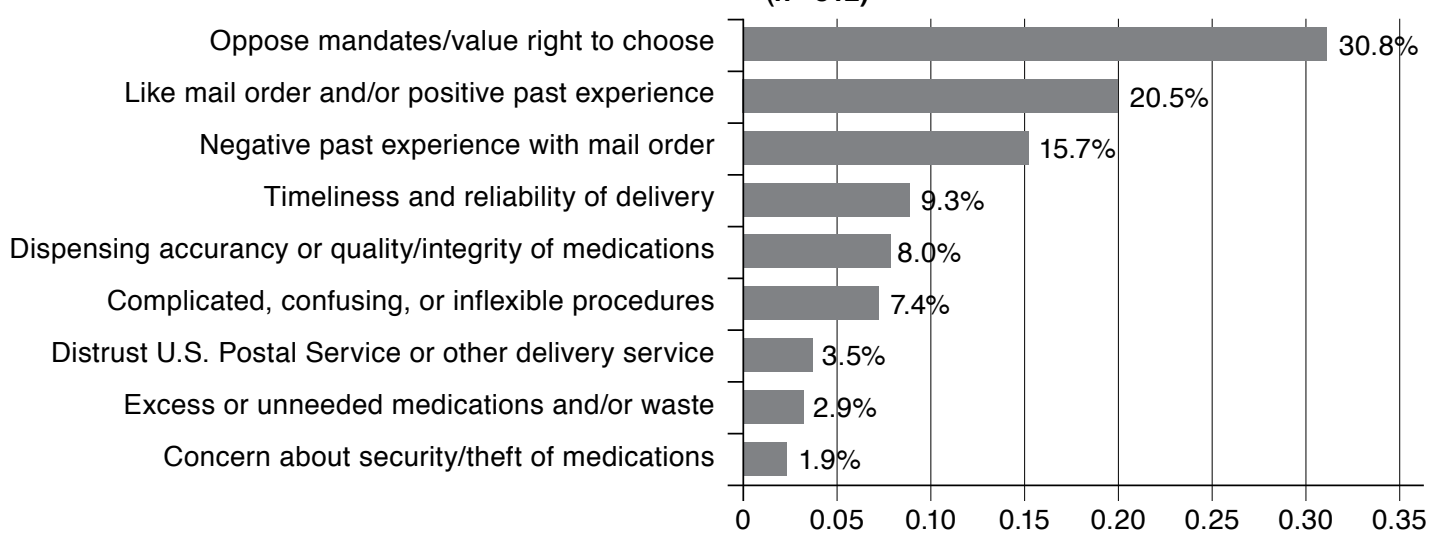

A frequently cited specific concern with mail order was the timeliness or reliability of delivery (9.3\%), especially during vacations or seasonal travel, when seniors may not have a consistent mailing address. Another frequently cited theme was concern about the accuracy of prescription processing and the quality or integrity of medications dispensed from mail order pharmacies (8.0\%). Complicated, confusing, or inflexible procedures used by mail order pharmacy were mentioned in $7.4 \%$ of comments, with concerns regarding the unhelpfulness of customer service personnel and inflexible automatic refill policies being commonly cited examples. Other concerns related to a distrust of the U.S. Postal Service or other delivery services (3.5\%), excess or unneeded medications being dispensed (2.9\%), and concerns about the theft of medications from mailboxes (1.9\%).

\section{Discussion}

As the role of mail service pharmacy in prescription benefit plans continues to be discussed, it is appropriate to solicit input and insight from those who are most affected by policies that would encourage or mandate its use. The results of this study suggest that elderly Americans are practical and pragmatic about the question. While most see a role for mail service pharmacy, they are also keenly aware of its limitations.

Community pharmacists have frequently expressed the concern that mandating the use of mail service pharmacy for long-term maintenance medications could potentially drive some pharmacies out of business. Requiring patients to obtain their chronic maintenance medications through a mail service pharmacy could result in insufficient volume to allow some 
community pharmacies to remain financially viable. If so, the impact would be felt most acutely by residents of rural areas, who may not have a convenient alternative source for immediate medication needs.

This study found that seniors living in rural areas have significantly greater concerns than their counterparts in nonrural areas about lost or stolen medications, receiving the exact medication the physician prescribed, and the effects of exposure to heat, cold, or moisture. Each of these concerns reflects the reality that older Americans in rural areas face in terms of the reliability and security of their mail delivery and the physical conditions to which their mail is routinely exposed. A much finer point was placed on these concerns in the numerous comments that were provided by seniors who live in rural areas.

When respondents were asked if they would oppose mandated mail order if it would lead to closure of the local community pharmacy they rely on for immediate medication needs, $83.7 \%$ responded affirmatively. When they were subsequently asked to indicate the highest level of risk they were willing to accept of this eventuality, respondents indicated an unwillingness to accept more than about a 4-in-10 chance of losing their local pharmacy as a result of mail order. Although these results do not validate the fears that mail order actually would threaten the financial viability of some community pharmacies, it does confirm that older Americans are relatively risk averse to this possibility, including those who regularly use mail order.

\section{Limitations}

The differences between the attitudes of mail order users and nonusers (Table 3) deserve further discussion. It is tempting to conclude that responses by users are more informed and therefore more accurate. However, it is equally likely that the differences observed are not the effect of experience with mail order but rather were the cause of that experience. That is, it is possible that seniors who had a pre-existing positive attitude toward mail order and were already reconciled to and accepting of its limitations were more likely to use mail order than those who were less favorably inclined. Because of the uncertainty regarding whether experience with mail order is a cause or an effect of respondent attitudes, these results should be interpreted with caution.

Respondents to the survey appeared to be representative of the national random sample that was used in the study. Moreover, there was no indication of possible nonresponse bias in the results of the analysis of early versus late responders. Still, the response rate for this study was less than optimal and this should be considered before generalizing the results to all Medicare-eligible persons.

\section{Conclusions}

The results of this study suggest that many seniors believe they have needs that cannot be adequately met by mail service or have relationships with local pharmacies and pharmacists that are important for maintaining their health and well-being. As a result, seniors are relatively risk averse when it comes to the loss of their local community pharmacies, indicating that, on average, they would oppose a mandatory mail order provision if there were greater than about a 4-in-10 chance that it would lead to the closure of their local pharmacies.

Beyond their specific concerns about mail service pharmacy, most seniors appear to oppose any restrictions on their freedom to use the pharmacy of their choice as a matter of general principle. This opposition is evidenced even among those who use and are generally satisfied with mail service pharmacy and should be considered by payers, policymakers, and benefit plan managers who may consider mandating mail service pharmacy for senior Americans.

\section{Authors}

MICHAEL T. RUPP, PhD, BPharm, FAPhA, is Professor of Pharmacy Administration, Midwestern University, College of Pharmacy-Glendale, Glendale, Arizona.

AUTHOR CORRESPONDENCE: Michael T. Rupp, PhD, BPharm, FAPhA, College of Pharmacy-Glendale, 19555 N. 59th Ave., Glendale, AZ 85308. Tel.: 623.572.3528;

E-mail:mtrupp@midwestern.edu.

\section{DISCLOSURES}

This study was funded by the National Community Pharmacists Association (NCPA) Foundation and approved by the Midwestern University Institutional Review Board. Rupp reports that he has received a consulting fee from NCPA and received payment from Virginia Commonwealth University for consultancy on an unrelated study funded by NCPA.

\section{REFERENCES}

1. Horgan C, Goody B, Knapp D, Fitterman L. The role of mail service pharmacies. Health Affairs. 1990;9(3):66-74.

2. National Association of Chain Drug Stores. 2011-2012 chain pharmacy industry profile. Alexandria, VA. 2011. Available through NACDS at www. nacds.org.

3. Schommer JC, Mott DA, Hansen RA, Cline RR. Selected characteristics of senior citizens' prescription drug payment and procurement in 1998 and 2001. J Manag Care Pharm. 2003;9(5):408-15. Available at: http://www.amcp org/WorkArea/DownloadAsset.aspx?id=6862

4. Roebuck MC, Liberman JN. Impact of pharmacy benefit design on prescription drug utilization: a fixed effects analysis of plan sponsor data. Health Serv Res. 2009:44:988-1009.

5. National Business Group on Health. Survey report: large employers' 2011 health plan design changes. August 2010. Available at: www.businessgrouphealth.org/pub/f314abb8-2354-d714-51f7-315a5al4fa20. Accessed June 20, 2013. 
6. Pharmacy Benefit Management Institute. 2012-2013 prescription drug benefit cost and plan design report. Available at: www.benefitdesignreport com. Accessed June 20, 2013.

7. Carroll NV, Brusilovsky I, York B, Oscar R. Comparison of costs of community and mail service pharmacy. J Am Pharm Assoc. 2005;45(3):336-43.

8. Jonsrud M, Lawson KA, Shepherd MD. Comparison of mail order with community pharmacy in plan sponsor cost and member cost in two large pharmacy benefit plans. J Manag Care Pharm. 2007;13(2):122-34. Available at: http://www.amcp.org/WorkArea/DownloadAsset.aspx?id=7541.

9. Linton A, Garber M, Fagan NK, Peterson M. Factors associated with choice of pharmacy setting among DoD health care beneficiaries aged 65 years or older. J Manag Care Pharm. 2007;13(8):677-86. Available at: http:// www.amcp.org/WorkArea/DownloadAsset.aspx?id=7729.
10. Liberman JN, Wang Y, Hutchins DS, Slezak J, Shrank WH. Revealed preference for community and mail service pharmacy. J Am Pharm Assoc. 2011;51:50-57.

11. 2012 U.S. pharmacy study. J.D. Power and Associates. September 27, 2012. Available at: http://www.jdpower.com/content/pressrelease/OUn2YoA/2012-u-s-pharmacy-study.htm. Accessed June 20, 2013.

12. Census Regions, Census Divisions, and Their Constituent States. Available at: http://www.census.gov/geo/www/geo_defn.html\#CensusRegion. 13. Nunnally JC. Psychometric Theory. New York: McGraw-Hill; 1978. 14. 2012 End of Year Zip Code File. Available at: http://www.cms.gov/ Medicare/Medicare-Fee-for-Service-Payment/AmbulanceFeeSchedule/index. html?redirect=/ambulancefeeschedule. 